\title{
Membership and Fees 2000 Admission et cotisation
}

Membership in either the Canadian Political Science Association and/or the Société québécoise de science politique includes a subscription to the Canadian Journal of Political Science. Joint membership or Société-only membership also includes a subscription to the Société's journal Politique et Sociétés.

There are two levels of membership fees. Income level stated refers to gross annual income (before taxes). Members may subscribe to Canadian Public Policy at a special rate.

La cotisation versée à l'Association canadienne de science politique et/ou à la Société québécoise de science politique donne droit à un abonnement à la Revue canadienne de science politique. L'adhésion aux deux organismes ou à la Société seulement donne également droit à un abonnement à la revue de la Société, Politique et Sociétés.

Il y a deux niveaux de cotisation dans chaque catégorie. La cotisation est fonction de votre revenu annuel brut (avant impôt). En tant que membre il vous est possible de vous abonner à un tarif avantageux à Analyse des politiques.

\begin{tabular}{|c|c|c|}
\hline $\begin{array}{l}\text { Choice of Associations/ } \\
\text { Choix d'associations }\end{array}$ & $\begin{array}{l}\text { Students and any other person } \\
\text { earning under } \$ 30,000 \text { annually } \\
\text { Etudiants et toute autre } \\
\text { personne dont le revenu annuel } \\
\text { ne dépasse pas } 30000 \$\end{array}$ & $\begin{array}{l}\text { All other } \\
\text { members/ } \\
\text { Tous les } \\
\text { autres } \\
\text { membres }\end{array}$ \\
\hline CPSA only / ACSP seulement & $\$ 35$ & $\$ 100$ \\
\hline SQSP seulement / only & $\$ 35$ & $\$ 95$ \\
\hline Joint/conjoint CPSA/ACSP-SQSP & $\$ 45$ & $\$ 110$ \\
\hline \multicolumn{3}{|c|}{ Membership fees are non-refundable. / Les cotisations ne sont pas remboursables. } \\
\hline \multicolumn{3}{|c|}{$\begin{aligned} \text { Institutional subscription }- & \$ 65(+15 \% \text { HST in Nova Scotia, New Brunswick and } \\
& \text { Newfoundland; }+7 \%[118835289 \mathrm{RT}] \text { elsewhere in } \\
& \text { Canada); } \$ 85 \text { (US funds) in all other countries }\end{aligned}$} \\
\hline \multicolumn{3}{|c|}{$\begin{array}{c}\text { Abonnement institutionnel- }-65 \$(+15 \% \text { TVH dans les provinces suivantes : Nouvelle- } \\
\text { Ecosse, Nouveau-Brunswick et Terre-Neuve; }+7 \% \\
{[118835289 \mathrm{RT}] \text { ailleurs au Canada; } 85 \$ \text { (devise }} \\
\text { américaine) dans tout autre pays }\end{array}$} \\
\hline
\end{tabular}

For information, please write: /

Pour de plus amples renseignements, veuillez vous adresser à :

Canadian Journal of Political Science /

Revue canadienne de science politique

\#204-260, rue Dalhousie Street

Ottawa, Ontario KIN 7E4 